\title{
O juramento de fraternidade de Robert Castel*
}

\author{
Frédéric Blondel ${ }^{\mathrm{I}, 1}$ e Sabine Delzescaux ${ }^{\mathrm{II}, 2}$ \\ ${ }^{\mathrm{I}}$ Université Paris-Diderot (Paris, França) \\ ${ }^{\text {II }}$ Université Paris-Dauphine (Paris, França)
}

\begin{abstract}
Contrariamente às concepções liberais, segundo as quais apenas o indivíduo faz escolhas e corre riscos, penso que o indivíduo é um sujeito social. Todos nós somos atravessados pela história. Isso não é apenas uma encenação. Isso marca profundamente nossas escolhas, nossos amores, nossas dores. Temos uma dívida com a história.

Robert Castel, L'humanité (entrevista publicada em 14 de março de 2013).
\end{abstract}

$\mathrm{R}$ obert Castel era uma personalidade, um grande homem. E, como todo grande homem, sabia que a grandeza é feita de pequeninas coisas que freiam nossa vaidade, e é por isso que tal qualificação, sem dúvida, o levava a sorrir e falar das coisas com bom humor. "Os vícios e as virtudes, tão imperfeitos", como dizia Éluard, lembram que a superfície de que é feito o homem não apresenta senão asperezas, como um jogo de sombras e luzes. Robert Castel sabia praticar a arte das pequenas nuances sem fazer concessões, e não dizia outra coisa quando evocava, nos termos que lhe eram próprios, a fragilidade estrutural dos corpos sociais, sua vulnerabilidade, as ameaças de desagregação que pesavam sobre suas solidariedades, apesar de estas tomarem formas sempre múltiplas e renovadas. Mostrar-se atento a essa questão, de forma distanciada, era certamente uma das exigências fortes no exercício de seu ofício de sociólogo, mas não se tratava apenas disso. Do mundo que o viu nascer, o "mundo das pessoas comuns", ele guardara essa memória das coisas frágeis. E se ele julgava que era seu dever, como homem de ciência, mostrar que a marginalidade jamais se observa em si, mas é fruto dos processos sócio-históricos que devemos analisar, ele sabia bem, por experiência própria, como menino que tão cedo se tornou órfão, o que é a dissolução das "proteções de proximidade", e não se esqueceu de nada sobre a possível fraternidade dos homens e de sua influência no curso da vida. Ele dizia que foi devido a um acontecimento em sua trajetória social, quando tinha 12 ou 13 anos, que foi levado a construir sua vida como intelectual. Isso ocorreu quando ele preparava um exame de aptidão profissional, como ajustador mecânico, ofício que o destinava a inscrever-se na continuidade da história de sua classe social de origem. Foi seu professor de matemática, um certo Buchenwald, quem o chamou e encorajou, contra toda expectativa, a fazer o ensino médio. Contra toda expectativa porque o caminho parecia estar traçado para ele. Além disso, o homem que os alunos chamavam de "Buchenwald" 3 porque era um morto-vivo ${ }^{4}$ (era assim que Jorge Semprun chamava os sobreviventes dos campos da morte), parecia-lhe não só triste e severo, mas também antipático. Esse professor o fazia ir regulamente ao quadro negro para fazer os exercícios de matemática que ele, ainda aluno do ensino fundamental, não sabia fazer. Por isso, ele experimentava um sentimento de medo diante do professor, misturado com desconfiança e rancor. Isso o impedia de ver a amabilidade que, na realidade, o professor sempre demonstrava. Estimulando-o a entrar para o ensino médio e tentar sua sorte, esse

\footnotetext{
* Publicado originalmente na seção "homenagens" do número especial sobre psicossociologia do trabalho da Nouvelle Revue de Psychosociologie, 15 (1), 273-276, 2013. DOI: 10.3917/nrp.015.0273

1 Maître de conférence em sociologia na Universidade Paris-Diderot e agregado ao Laboratoire de Changement Social.

2 Maître de conférence em sociologia na Université Paris-Dauphine e agregada ao Laboratoire du LEDa-LEGOS.

3 Nome de um dos maiores campos de concentração nazistas, situado no leste da Alemanha (N. T.).

4 Traduzimos como "morto-vivo" o termo francês renenant, que significa algo como "alguém que voltou da morte", "um fantasma" (N. T.).
} 
antigo resistente comunista, de apelido sinistro, foi quem naquele dia abriu-lhe as "portas da liberdade". Retomando sua fórmula, ele foi "seu professor de liberdade". Por certo, Robert Castel não era um bom aluno em matemática, mas era bom em francês e a literatura era seu refúgio; os livros lhe ofereciam uma sensação de alívio em relação ao seu desespero de criança: sua mãe tinha morrido quando ele fez 9 anos; seu pai, quando ele tinha 11. Foram sua irmã e seu cunhado que o acolheram. Esse cunhado, eletricista de profissão, também o ajudou a emancipar-se de sua condição social de origem, sustentando-o e apoiando-o em seu projeto que era considerado louco para uma criança de sua condição - de prosseguir seus estudos em um curso superior. ${ }^{5}$ A brilhante carreira de Robert Castel justificou essa bifurcação, pois a obra que ele tão elegantemente nos deixou é profunda e consistente.

A consistência dessa obra e a robustez de suas demonstrações têm a ver fundamentalmente com o viés histórico escolhido por Robert Castel e com o princípio epistemológico que está ali subentendido: para compreender e explicar o mundo, é preciso mantê-lo a distância. Além disso, a historicização dos objetos de pesquisa que ele elege é que o conduz, na trilha de pensadores como Michel Foucault e Norbert Elias, a dedicar uma atenção maior ao passado, cuja compreensão é necessária para compreendermos o presente. Pois é a partir desse presente que o futuro corre grande risco de escapar aos homens, quando estes não avaliam as consequências de suas ações atuais. A profundidade de seu trabalho repousa também numa hipótese forte que guia o conjunto de sua reflexão: a hipótese de que a liberdade do sujeito social resulta das condições sociais e históricas que a tornam possível.

Evidentemente, é difícil saber se a elaboração de tal hipótese se inspira na análise de Robert Castel sobre a atitude de seu professor de matemática e da incidência desse fato sobre sua trajetória social e familiar, ou se o encadeamento dos acontecimentos que ele narra resulta dessa hipótese geral que ele aplicaria à sua própria trajetória. No entanto, e seja qual for o caminho tomado para a construção dessa hipótese, pode-se dizer, sem trair seu pensamento, que existe uma forte coerência entre a experiência singular que ele relata e o objeto de pesquisa que privilegia, ou seja, o estudo das condições da liberdade do indivíduo. Robert Castel sabia de onde vinha e propunha uma versão coerente de sua trajetória. O conjunto de seu trabalho traz a marca de sua afeição, de seu respeito e reconhecimento por aqueles que contribuíram para a sua emancipação, como se o homem, na realização de sua obra, fosse guiado por um juramento de fraternidade em relação àqueles que, por suas condições de vida e de socialização, estavam abandonados à própria sorte e não conseguiram escapar da vulnerabilidade e da precariedade em que nasceram e permaneceram. Nisso, Robert Castel é um sociólogo da socialização, atento como Norbert Elias à internalização das pressões sociais que, como ele ressaltava, iam "até o ponto de constituir a trama de nossos afetos mais pessoais". ${ }^{6}$ Se os sujeitos são ativos nos processos de subjetivação, os determinismos históricos que eles subjetivam se atualizam sempre nos processos de socialização que experienciam. Para Castel, daí vem a importância de um acontecimento ou de um encontro que torne possível a bifurcação. Daí também resulta seu interesse pela análise das "situações instáveis" e frágeis, aquelas que abrem caminho às bifurcações, sem que possamos predizer se elas vão desembocar na afiliação ou na desfiliação individual. No entanto, seu trabalho mostra que em geral o risco de desfiliação refere-se ao indivíduo mais exposto à insegurança social, econômica e simbólica, e que a fragilidade do indivíduo aumenta à medida que desaparecem coletivos protetores. De certa maneira, Robert Castel aplicou a si mesmo, com toda humildade, essa hipótese de trabalho. Não que suas qualidades pessoais devam ser subestimadas, basta vermos até onde ele chegou, mas, segundo ele mesmo, estas não poderiam, sozinhas, mudar sua trajetória de vida. Para que o processo de subjetivação permita ao sujeito social - que Robert Castel sempre concebeu como um sujeito em

5 Cf. "Le subjectif et l'objectif", In Itinéraires de sociologues (suite...), Histoires de vie et choix théoriques. Cahier du Laboratoire de Changement Social, 12, maio de 2007; À Buchenwald, Revue Esprit, julho de 2007; Témoignage: à Buchenwald, In Changements et pensées du changement. Echanges avec Robert Castel (Organizado por Robert Castel e Claude Martin). Paris: Ed. La Découverte, 2012.

6 Robert Castel \& Claude Martin, Changements et pensées du changement, p. 340. 
interação com o mundo - entrar em novo registro de existência social, o indivíduo deve encontrar e defrontar-se com as condições sociais que tornam possível a emergência e a realização desse registro. Como ele gostava de dizer, "a consciência de si não é um dado espontâneo da consciência", ela aparece como tal, quando a socialização, processo pelo qual se dá o ajustamento da subjetividade às condições sociais objetivas, é colocada à prova por experiências que não fazem parte dos esquemas habituais de pensamento. Sua familiaridade com a psicologia e a sociologia clínica também tinha relação, em parte, com a vontade de compreender, do ponto de vista do indivíduo, os suportes que este mobiliza no aqui e agora para escolher uma direção quando uma bifurcação aparece e aponta um novo horizonte, seja este para melhor ou para pior.

Robert Castel estava convencido de que a Macro-história, da qual somos produto, é sempre atravessada pela Micro-história, e foi assim que as coisas aconteceram com ele. Ele não tirou nenhuma glória vã de sua notoriedade, e sempre se recusou a considerar que foi por si só que ele chegou aonde chegou no campo social e na trajetória social que tornaram possível esse lugar. É aqui que o homem de ciência se funde com o homem de honra, uma vez que, para Castel, "ser responsável pela própria vida" é uma afirmação que pode não passar de simples discurso performativo, jogando sobre os indivíduos mais vulneráveis a responsabilidade por suas próprias situações. Ora, a marginalidade é, antes de tudo, marginalização. Este é o nome, dizia ele, que se pode dar às formas mais frágeis da vulnerabilidade popular. ${ }^{7}$ Em uma época em que as zonas de integração não cessam de conhecer fissuras, e as zonas de vulnerabilidade e de desfiliação não cessam de aumentar, época em que as lutas agonísticas estão em alta e em que o fervor meritocrático tende a fazer que os indivíduos creiam que só os seus talentos e seu querer fazem o jogo do social, as meditações castelianas oferecem a nossas incertezas os mais belos frutos dessa vulnerabilidade popular com a qual esse autor tanto se preocupava. Adeus, senhor Castel, e obrigado. 